\title{
A!
}

This is an electronic reprint of the original article.

This reprint may differ from the original in pagination and typographic detail.

Blume, Fabian; Sprengart, Petra; Deska, Jan

\section{Lipase-Induced Oxidative Furan Rearrangements}

\section{Published in:}

Synlett

DOI:

10.1055/s-0036-1591889

Published: 15/01/2018

Document Version

Peer reviewed version

Published under the following license:

Unspecified

Please cite the original version:

Blume, F., Sprengart, P., \& Deska, J. (2018). Lipase-Induced Oxidative Furan Rearrangements. Synlett, 29(10), 1293-1296. https://doi.org/10.1055/s-0036-1591889

This material is protected by copyright and other intellectual property rights, and duplication or sale of all or part of any of the repository collections is not permitted, except that material may be duplicated by you for your research use or educational purposes in electronic or print form. You must obtain permission for any other use. Electronic or print copies may not be offered, whether for sale or otherwise to anyone who is not an authorised user. 


\section{Lipase-induced Oxidative Furan Rearrangements}

\author{
Fabian Blume ${ }^{a}$ \\ Petra Sprengart ${ }^{\mathrm{b}}$ \\ Jan Deska*a \\ a Department of Chemistry \& Materials Science, \\ Aalto-yliopisto, Kemistintie 1, 02150 Espoo, Finland. \\ b Department of Chemistry, Universität zu Köln, \\ Greinstrasse 4, 50939 Cologne, Germany. \\ jan.deska@aalto.fi
}

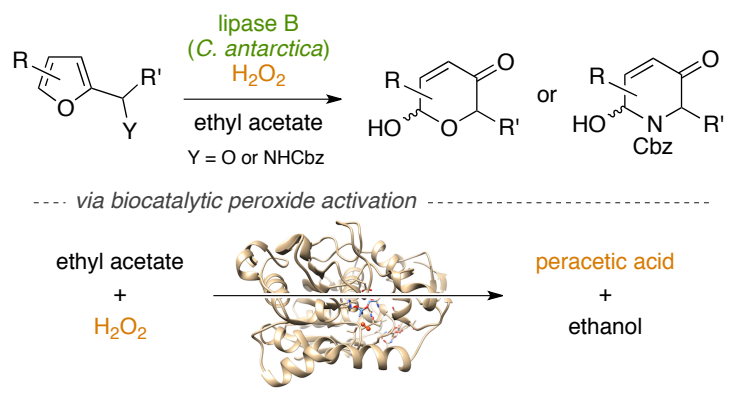

\section{Received:
Accepted: \\ Published online: \\ Abstract Lipase B from Candida antarctica catalyzes the oxidative ring expansion of furfuryl alcohols using aqueous hydrogen peroxide to yield functionalized pyranones under mild conditions. The method further allows for the preparation of corresponding piperidinone derivatives by enzymatic rearrangement of $\mathrm{N}$-protected furfurylamines. \\ Key words Achmatowicz, ring expansion, furan, pyranone, synthetic} methodology, heterocyclic chemistry

The rich chemistry of furans as readily available organic building blocks, and particularly their prominent role as one of the major players in modern lignocellulose biorefinery, ${ }^{1}$ have led to an increasing interest in their use for the construction of more complex molecular architectures. ${ }^{2}$ Here, the oxidative ring expansion of furfuryl alcohols and amines to six-membered, highly functionalized $\mathrm{O}$ - and $\mathrm{N}$-heterocycles, respectively, represents a paramount example for the synthetic utility of the furyl platform. Based on the original reports using classical oxidants by Cavill $\left(\mathrm{Br}_{2}\right.$, 1969), ${ }^{3}$ Achmatowicz $\left(\mathrm{Br}_{2}, 1971\right),{ }^{4}$ or Lefebvre (peracetic acid, 1972), ${ }^{5}$ a wide repertoire of methodologies for the selective furan oxidation has been developed over the years, ${ }^{6}$ and the Achmatowicz rearrangement has reached an important role in modern organic synthesis. ${ }^{7}$ In 2014, we reported for the first time of an aerobic biocatalytic version of this reaction featuring a direct furan oxygenation by chloroperoxidase. ${ }^{8}$ While this method stood out with respect to catalytic turnover, selectivity in presence of other oxidation-labile functional groups and the ability to act in more complex biocatalytic cascades, ${ }^{9}$ chloroperoxidase from Caldariomyces fumago generally fails to convert sterically biased furfuryl substrates bearing branched alkyl side chains or substituents on the heterocyclic core. We therefore became interested in the use of enzyme-generated diffusible redox mediators that would allow for the transfer of oxidation equivalents outside the biocatalyst's active site as previously illustrated in successful examples of this approach including enzyme-mediator couples such as haloperoxidase/hypobromite, ${ }^{10}$ or laccase/TEMPO. ${ }^{11}$ Inspired by our observation that lipases can act as peracid-generating catalyst in hydrogenperoxide-containing acetate buffer, ${ }^{8,12}$ the aim of this study was to establish a preparatively simple Lefebvre-type Achmatowicz protocol based on the enzyme-induced peroxide activation. Here, the combination of Candida antarctica lipase B and hydrogen peroxide in aliphatic esters (as acyl donor and solvent) has already been shown to be a powerful system for the in situ generation of peracetic acid to provide mild reaction conditions for Prilezhaev-type epoxidations, ${ }^{13}$ Baeyer-Villiger reactions, ${ }^{14}$ and other electrophilic oxygenations, ${ }^{15}$ and was therefore considered a promising tool also for the oxygenative ring rearrangement of furan-based alcohols and amines.

The 5-methyl substituted furfuryl alcohol 1a was chosen as model substrate for the optimization study since it proved to be particularly challenging in the Achmatowicz oxidation by the chloroperoxidase/oxidase couple. The original protocol by Allais, using aqueous hydrogen peroxide in ethyl acetate in presence of lipase B from Candida antarctica and a so-called solid buffer based on (4-(2-hydroxyethyl)-1-piperazineethanesulfonic acid (HEPES), ${ }^{14 a}$ provided reasonable conversion of the alcohol $1 \mathrm{a}$ and delivered the desired pyranone $\mathbf{2} \mathbf{a}$ in $56 \%$ yield (Table 1 , entry 1 ). We also tested an alternative solid buffer consisting of mono and dibasic phosphate as well as $\mathrm{MgSO}_{4}$ as desiccant which, however, resulted in reduced product formation (Table 1, entry 2). With the rational to minimize the competition between the peroxide and water in the perhydrolysis process, next, $\mathrm{MgSO}_{4}$ was used as sole additive leading to both increased conversion and yield of $\mathbf{2 a}$ (Table 1 , entry 3). At higher substrate concentrations, excellent levels of conversion were maintained but the selectivity for the pyranone $\mathbf{2 a}$ dropped significantly (Table 1 , entry 4 \& 5). Surprisingly, even in absence of any desiccant (or other additive), very good conversions could be conserved (Table 1 , entry 6 ), and minor modifications with regard to the equivalents of $\mathrm{H}_{2} \mathrm{O}_{2}$ rendered a high-yielding, selective, enzyme-induced Achmatowicz protocol (Table 1, entry 7 $\& 8)$. Instead of aqueous peroxide $(50 \% \mathrm{w} / \mathrm{w})$, also fine-powdered urea $\mathrm{H}_{2} \mathrm{O}_{2}$ could be employed, with slightly reduced selectivities (Table 1 , entry $10 \& 11$ ). As one crucial factor to achieve reproducible results and high product yields, it was necessary to remove excess peroxides by the addition of aqueous catalase prior to purification. 


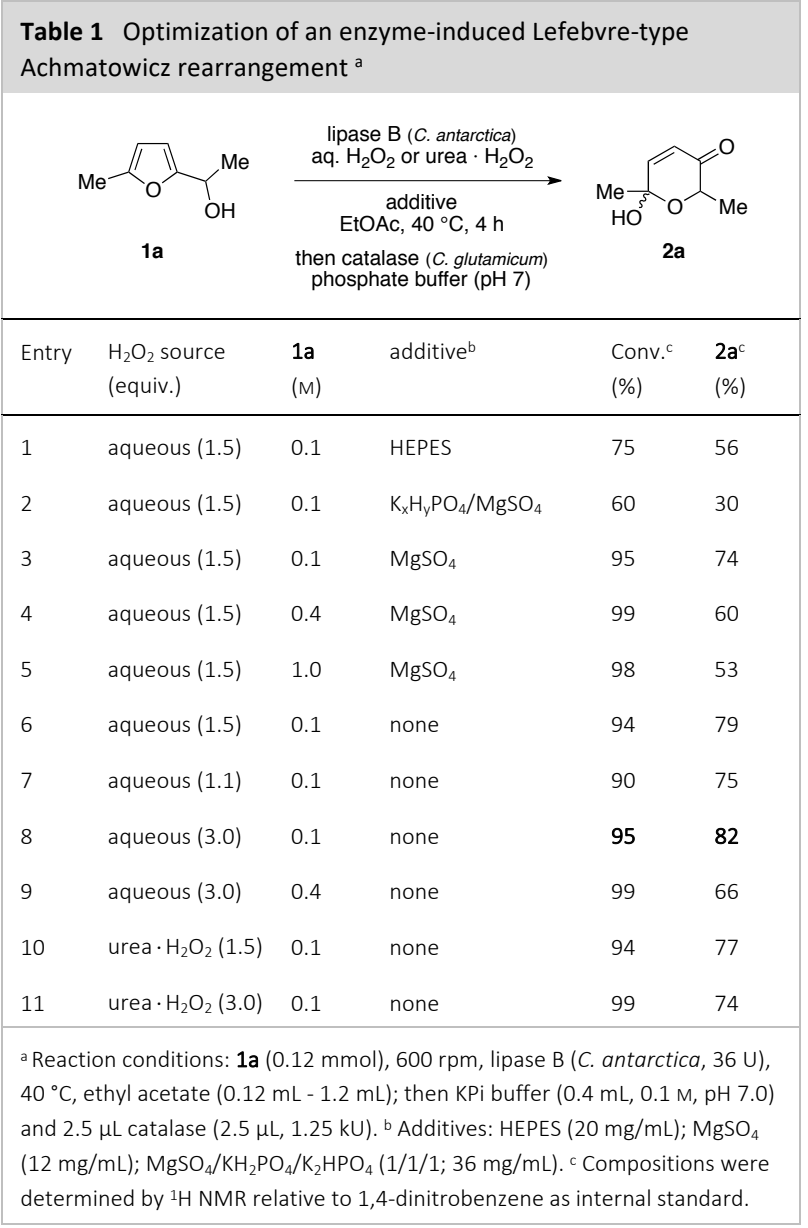

The previously developed chloroperoxidase-catalyzed Achmatowicz protocol did not only exhibit poor performance on 5-substituted furfuryl alcohols such as 1 a but also other substitution patterns were not well tolerated in a direct enzymatic oxygen transfer reaction. ${ }^{8}$ Thus, a comparative study on a wider set of furan substrates on a preparative $5 \mathrm{mmol}$ scale was conducted in order to point out the pros and cons of either method (Scheme 1). 1a was rapidly consumed by the lipase/peracid couple and pyranone 2 a could be isolated in $74 \%$ yield after only $4 \mathrm{~h}$. All monosubstituted furans $(\mathbf{1} \mathbf{b} \mathbf{-} \mathbf{1}$ ) reacted more sluggishly and close to full conversion was only achieved after around $24 \mathrm{~h}$. Comparing the outcome of the biocatalytic syntheses of simple $n$-alkyldecorated pyranones (2b-2e), increase of chain length clearly resulted in reduced yields for protocol $\boldsymbol{B}$ (chloroperoxidasemediated) while the lipase-mediated method $\boldsymbol{A}$ exhibited a generally good performance particularly for the higher homologues. A similar picture was obtained for different branching patterns where both isobutyl derivative $\mathbf{2 g}$ and the geminally dimethylated $\mathbf{2} \mathrm{h}$ were only accessible in high yields by the peracidmediated reaction $\boldsymbol{A}$. As for the model substrate $\mathbf{1 a}$, also methylation in the 3-position of the furfuryl alcohols rendered the substrates inactive under the conditions provided by method $B$ whereas decoupling of the enzymatic principle with the oxidizing entity in form of a diffusible redox mediator $(\boldsymbol{A})$ enabled conversion of furans such as $\mathbf{1 i}$ or $\mathbf{1} \mathbf{j} .{ }^{16}$ Worth noting, the formation of the corresponding ketolactones, from over-oxidation of the hemiacetal as reported for e.g. the laccase/TEMPO system, ${ }^{11}$ was never observed in transformations based on either $\boldsymbol{A}$ or $\boldsymbol{B}$. On the other hand, a series of functional groups such as esters and olefins were well tolerated by the chloroperoxidase which would be readily attacked by the lipase and/or peracetic acid.

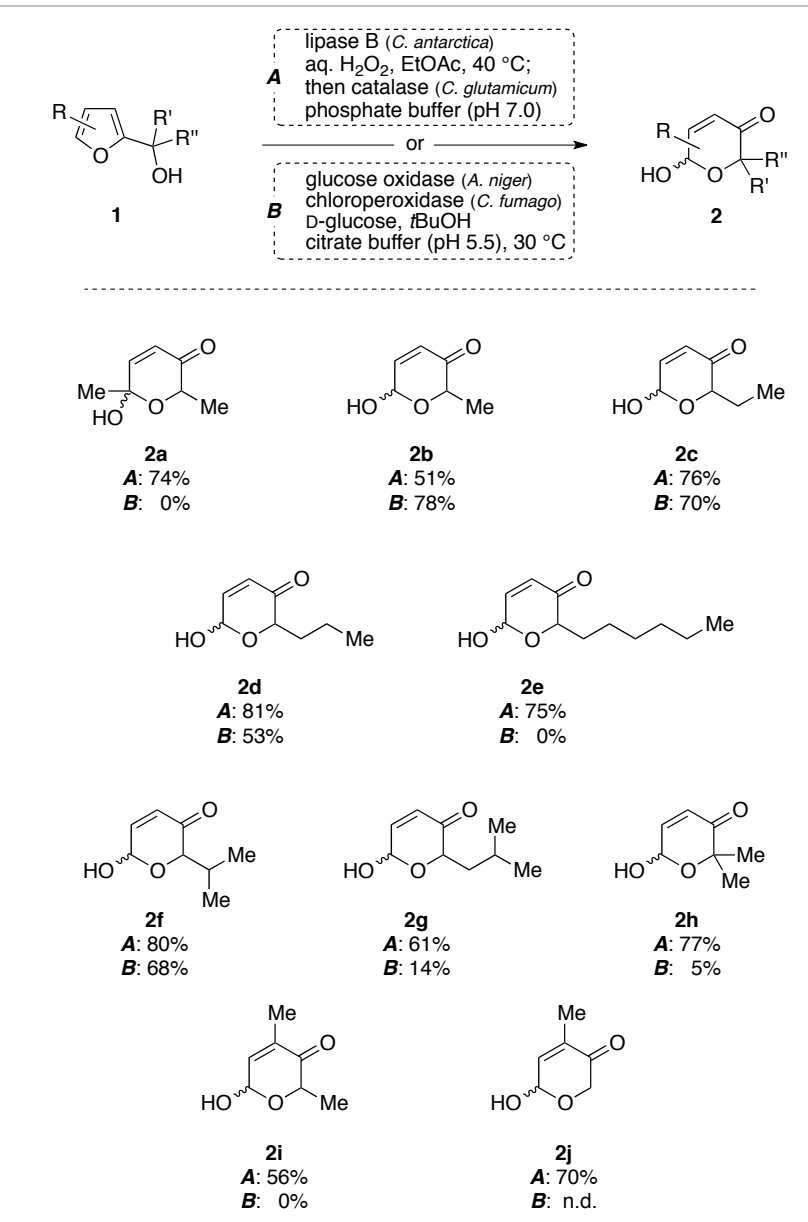

Scheme 1 Substrate scope: comparison between peracetic acid-mediated (A) and non-mediated (B) enzymatic Achmatowicz protocols.

Encouraged by the broad scope and lack of any steric bias of the lipase-induced oxidation of furfuryl alcohols to pyranones, we expanded the study to related $\mathrm{N}$-protected furfurylamine derivatives,${ }^{17}$ that would give rise to synthetically equally important piperidinones. Gratifyingly, lipase B from C. antarctica readily converted monosubstituted furans carrying benzyl carbamate moieties to the corresponding $\mathrm{N}$-Cbz-protected $\mathrm{N}$-heterocycles $4 \mathrm{a}$ and $\mathbf{4 b}$ in $65 \%$ and $40 \%$ yield, respectively (Scheme 2 ). As in the case of furfuryl alcohols, also core-substituted furans like 3c underwent rapid oxidative cleavage by the lipase-mediated peracid-generating system. However, as already observed in various other studies, ${ }^{18}$ ring closure of the resulting diketones to the hemiaminals is hampered and also in our case, the corresponding isomerized E-configured acyclic enedione was obtained as major product. 


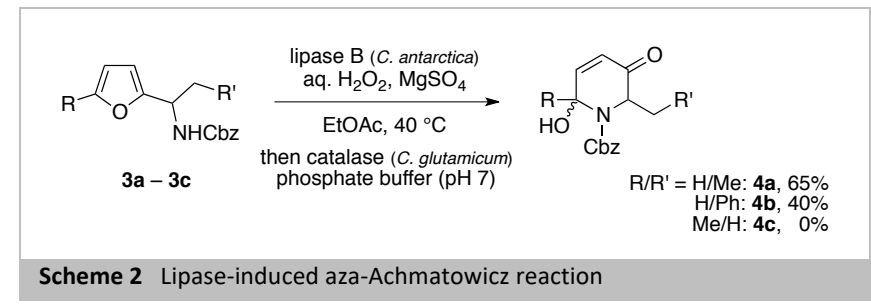

Although this and other studies evidently show the potential of lipases to act as mediator for the in situ generation of reactive oxidizing species, the family of lipase biocatalysts is certainly much more renowned for their ability to serve as resolution catalyst in the stereoselective acylation of secondary alcohols. We therefore envisaged that the combination of a kinetic resolution of furfuryl alcohols with the subsequent oxidative rearrangement in a one-pot fashion would offer a direct access to enantiomerically enriched pyranones. In practice, not only did the coupling of resolution ( $\left.\mathrm{k}_{\text {rel }}>300\right)$ and ring expansion proceed smoothly but the reaction sequence could even be extended by an iridium-catalyzed diastereoselective redoxisomerization ${ }^{19}$ to yield the naturally occurring $\partial$-hexanolide osmundalactone (5) in high stereochemical purity (Scheme 3). ${ }^{20}$ Here, all three steps are conducted in the same solvent individually induced by the sequential addition of the reagents/catalysts to the reaction mixture leading to an overall yield of $22 \%$ (relative to a theoretical yield of max. $50 \%$ due to the nature of kinetic resolutions).

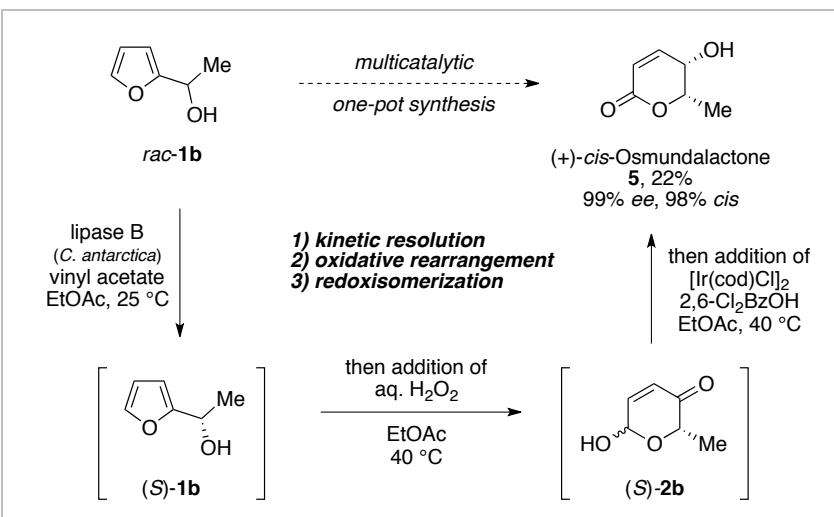

Scheme 3 Application in a stereoselective one-pot reaction cascade towards cis-Osmundalactone.

In summary, we have developed a practical, mild, and scalable protocol for the peracid-mediated Achmatowicz-type ring expansion of furfuryl alcohols. Making use of a lipase-catalyzed perhydrolysis of ethyl acetate and thus rendering the handling of stoichiometric amounts of peracetic acid obsolete, this approach represents a powerful and competitive addition to the toolbox of biocatalytic furan oxidations. The bioinduced rearrangement reaction proved to be broadly applicable on a variety of differently decorated furyl carbinols giving rise to pyranone building blocks in generally good yield. Moreover, the method was similarly effective in the corresponding aza-Achmatowicz reaction towards functionalized six-membered $\mathrm{N}$-heterocycles.

\section{Acknowledgment}

We gratefully acknowledge support by the Suomen Akatemia (298250), the Deutsche Forschungsgemeinschaft (DE1599/4-1) and by Carbolution Chemicals.

\section{Supporting Information}

Supporting information for this article is available online at...

\section{References}

(1) Kamm, B. Angew. Chem. Int. Ed. 2007, 46, 5056; Angew. Chem. 2007, 119, 5146.

(2) (a) Eicher, T.; Hauptmann, S.; Speicher, A. The Chemistry of Heterocycles, 3rd ed., Wiley-VCH: Weinheim, 2012; (b) AlvarezBuilla, J.; Vaquero, J. J.; Barluengo, J. Modern Heterocyclic Chemistry, 1st ed., Wiley-VCH: Weinheim, 2011.

(3) Cavill, G. W. K.; Laing, D. G.; Williams, P. J. Aust. J. Chem. 1969, 22, 2145.

(4) Achmatowicz Jr., O.; Bukowski, P.; Szechner, B.; Zwierzchowska, Z.; Zamojski, A. Tetrahedron 1971, 27, 1973.

(5) Lefebvre, Y. Tetrahedron Lett. 1972, 2, 133.

(6) Deska, J.; Thiel, D.; Gianolio, E. Synthesis 2015, 47, 3435.

(7) (a) Ghosh, A. K.; Brindisi, M. RSC Adv. 2016, 6, 111564; (b) van der Pijl, F.; van Delft, F. L.; Rutjes, F. P. J. T. Eur. J. Org. Chem. 2015, 4811.

(8) Thiel, D.; Doknić, D.; Deska, J. Nat. Commun. 2014, 5, 5278.

(9) Blume, F.; Liu, Y.-C.; Thiel, D.; Deska, J. J. Mol. Catal. B Enzym. 2016, 134, 280.

(10) Fernández-Fuego, E.; Younes, S. H. H.; van Rootselaar, S.; Aben, R. W. M.; Renirie, R.; Wever, R.; Holtmann, D.; Rutjes, F. P. J.; Hollmann, F. ACS Catal. 2016, 6, 5904.

(11) Asta, C.; Schmidt, D.; Conrad, J.; Förster-Frömme, B.; Tolasch, T.; Beifuss, U. RSC Adv. 2013, 3, 19259.

(12) Bernhardt, P.; Hult, K.; Kazlauskas, R. J. Angew. Chem. Int. Ed. 2005, 44, 2742; Angew. Chem. 2005, 117, 2802.

(13) (a) Kotlewska, A. J.; van Rantwijk, F.; Sheldon, R. A.; Arends, I. W. C. E. Green Chem. 2011, 13, 2154; (b) Ankudey, E. G.; Olivo, H. F.; Peeples, T. L. Green Chem. 2006, 8, 923; (c) (a) Carboni-Oerlemans, C.; Domínguez de María, P.; Tuin, B.; Bargeman, G.; van der Meer, A.; van Gemert, R. J. Biotechnol. 2006, 126, 140; (d) Rüsch, M.; Warwel, S. Org. Lett. 1999, 1, 1025.

(14) (a) Flourat, A. L.; Peru, A. A. M.; Teixeira, A. R. S.; Brunissen, F.; Allais, F. Green Chem. 2015, 17, 404; (b) Wang, X.-P.; Zhou, P.-F.; Li, Z.-G.; Yang, B.; Hollmann, F.; Wang, Y.-H. Sci Rep. 2017, 7, 44599; (c) Ríos, M. Y.; Salazar, E.; Olivo, H. F. Green Chem. 2007, 9, 459.

(15) (a) Wang, Z.; Chen, X.; Wang, C.; Zhang, L.; Li, F.; Zhang, W.; Chen, P.; Wang, L. Green Chem. Lett. Rev. 2017, 10, 269; (b) Bergler Bitencourt, T.; da Graça Nascimento, M. Green Chem. 2009, 11, 209.

(16) Representative experimental procedure: The appropriate furfuryl alcohol $(5 \mathrm{mmol})$ was dissolved in ethyl acetate $(50 \mathrm{~mL})$, and CAL-B (105 mg, $1.5 \mathrm{kU}$ ) and aqueous $\mathrm{H}_{2} \mathrm{O}_{2}(50 \% 858 \mu \mathrm{L}, 15 \mathrm{mmol}$ ) were added. The reaction mixture was placed on an orbital shaker at $40{ }^{\circ} \mathrm{C}$ (200 rpm). After $24 \mathrm{~h}$, phosphate buffer (15 mL, $100 \mathrm{mM}, \mathrm{pH} 7.0$ ) and catalase $(5 \mu \mathrm{L})$ were added and the mixture was shaken for further $15 \mathrm{~min}$. The organic phase was separated and the aqueous phase was extracted with ethyl acetate $(2 \times 20 \mathrm{~mL})$. The combined organic layers were dried over $\mathrm{Na}_{2} \mathrm{SO}_{4}$ and volatiles were removed under reduced pressure. The crude product was purified by flash column chromatography (hexane/EtOAc). 6-Hydroxy-2,2-dimethyl-2Hpyran-3(6H)-one $2 \mathrm{~h}$ : Purified by column chromatography $\left(\mathrm{SiO}_{2}\right.$, $n$-hexane/EtOAc $3 / 1$ to $2 / 1$ ) to give a cololess liquid $(547 \mathrm{mg}$, $3.85 \mathrm{mmol}, 77 \%) . \mathrm{R}_{f}=0.33$ (n-hexane/EtOAc, 2:1). ${ }^{1} \mathrm{H} \mathrm{NMR}\left(\mathrm{CDCl}_{3}\right.$, $400 \mathrm{MHz}): \partial[\mathrm{ppm}]=6.87(\mathrm{dd}, 3 \mathrm{~J}=10.3 \mathrm{~Hz}, 3 \mathrm{~J}=2.2 \mathrm{~Hz}, 1 \mathrm{H}), 6.07$ (dd, ${ }^{3} J=10.3 \mathrm{~Hz},{ }^{4} J=1.3 \mathrm{~Hz}, 1 \mathrm{H}$ ), $5.70-5.68(\mathrm{~m}, 1 \mathrm{H}), 3.38$ (br s, $1 \mathrm{H}), 1.49$ (s, $3 \mathrm{H}), 1.39$ (s, $3 \mathrm{H}) .{ }^{13} \mathrm{C} \mathrm{NMR}\left(\mathrm{CDCl}_{3}, 100 \mathrm{MHz}\right): \partial$ [ppm] $=198.9,145.7,126.6,88.0,79.5,26.6,23.9$. FT-IR (ATR): $v\left[\mathrm{~cm}^{-1}\right]=$ 
3402 (br), 2982 (w), 1681 (s), $1380(\mathrm{~m}), 1293(\mathrm{~m}), 1238(\mathrm{~m}), 1084$ (m), $1036(\mathrm{~s}), 924(\mathrm{~m})$

(17) Blume, F.; Albeiruty, M. H.; Deska, J. Synthesis 2015, 47, 2093.

(18) (a) Hodgson, R.; Kennedy, A.; Nelson, A.; Perry, A. Synlett 2007, 1043; (b) Ferrari, F. D.; Ledgard, A. J.; Marquez, R. Tetrahedron 2011, 67, 4988; (c) Haukaas, M. H.; O’Doherty, G. A. Org. Lett. 2001, 3, 401

(19) Wang, H.-Y.; Yang, K.; Bennett, S. R.; Guo, S.-R.; Tang, W. Angew. Chem. Int. Ed. 2015, 54, 8756; Angew. Chem. 2015, 127, 8880.

(20) (a) Yu, Y.-M.; Yang, J.-S.; Peng, C.-Z.; Caer, V.; Cong, P.-Z.; Zou, Z.-M.; Lu, Y.; Yang, S.-H.; Gu, Y.-C. J. Nat. Prod. 2009, 72, 921; (b) Chen, Y.; Tao, Y.; Lian, X.; Wang, L.; Zhao, Y.; Jiang, J.; Zhang, Y. Food Chem. 2010, 122, 1173

(21)

(22) 